\title{
A STUDY OF CHANNEL AND DELAY-BASED SCHEDULING ALGORITHMS FOR LIVE VIDEO STREAMING IN THE FIFTH GENERATION LONG TERM EVOLUTION-ADVANCED NETWORK
}

\author{
Liza Abdul LatifF ${ }^{1}$, Huda Adibah Mohd Ramli ${ }^{* *}$, ANi Liza ASNaWI ${ }^{2}$ \\ aNd Nur Haliza Abdul WaHab ${ }^{3}$ \\ ${ }^{1}$ Razak Faculty of Technology and Informatics, \\ Universiti Teknologi Malaysia, Kuala Lumpur, Malaysia \\ ${ }^{2}$ Department of Electrical and Computer Engineering, International Islamic University Malaysia, \\ Jalan Gombak, 53100 Kuala Lumpur, Malaysia \\ ${ }^{3}$ Faculty of Engineering, Universiti Teknologi Malaysia, Johor Bahru, Malaysia Malaysia
}

*Corresponding author: hadibahmr@iium.edu.my

(Received: $18^{\text {th }}$ June 2021; Accepted: $15^{\text {th }}$ July 2021; Published on-line: $4^{\text {th }}$ January 2022)

\begin{abstract}
This paper investigates the performance of a number of channel and delay-based scheduling algorithms for an efficient QoS (Quality of Service) provision with more live video streaming users over the Fifth Generation Long-Term EvolutionAdvanced (5G LTE-A) network. These algorithms were developed for use in legacy wireless networks and minor changes were made to enable these algorithms to perform packet scheduling in the downlink 5G LTE-A. The efficacies of the EXP and M-LWDF algorithms in maximizing the number of live video streaming users at the desired transmission reliability, minimizing the average network delay and maximizing network throughput, are shown via simulations. As the M-LWDF has a simpler mathematical equation as compared to the EXP, it is more favoured for implementation in the complex downlink 5G LTE-A.
\end{abstract}

ABSTRAK: Kertas ini menyiasat prestasi sebilangan saluran dan algoritma penjadualan berdasarkan kelewatan untuk penyediaan QoS (Kualiti Perkhidmatan) yang cekap dengan banyak pengguna video secara langsung melalui rangkaian Generasi Kelima Long-Term Evolution Advanced (5G LTE-A). Algoritma-algoritma yang disiasat di dalam kertas ini dicadangkan untuk digunakan dalam generasi rangkaian tanpa wayar yang lama dan sedikit perubahan dibuat untuk membolehkan algoritma ini menyokong penjadualan paket dalam downlink 5G LTE-A. Keberkesanan EXP dan M-LWDF algoritma dalam memaksimumkan jumlah pengguna pada kebolehpercayaan transmisi yang diinginkan dari streaming video secara langsung, meminimumkan kelewatan rangkaian, dan memaksimumkan truput rangkaian ditunjukkan melalui simulasi. Namun, dengan M-LWDF mempunyai formula matematik yang mudah dibandingkan dengan EXP, ia lebih sesuai untuk digunakan dalam downlink 5G LTE-A yang lebih kompleks.

KEYWORDS: scheduling algorithms; 5G; orthogonal frequency division multiple access; quality of service; long term evolution-advanced (LTE-A)

\section{INTRODUCTION}

Fifth Generation (5G) is the most current standard of wireless networks [1] deployed in Malaysia. 5G was expected to provide satisfactory Quality of Service (QoS) for a large 
number of users [2] and be more resilient in terms of network flexibility and (re)configurations. To date, there is no formal definition for $5 \mathrm{G}$ radio access networks, but the majority of the studies extended the Long-Term Evolution-Advanced (LTE-A) by embracing innovative features relevant to $5 \mathrm{G}$ (referred to as 5G LTE-A). The 5G LTE-A aggregates the available bandwidth (also known as Component Carriers (CCs)) to significantly increase data rates. Moreover, another important $5 \mathrm{G}$ feature for meeting the desired QoS for more mobile internet users is by packet scheduling. In each scheduling period, the packet scheduler in the downlink LTE-A uses a scheduling algorithm to choose the packets of a user for transmission on each radio resource on each CC.

The scheduling algorithms currently available in the extant literature are channelbased, delay-based, channel-and-delay-based or none of those. The decision whether to consider channel quality or packet delay or neither depends on the network performance to be maximized or the desired QoS to be satisfied. For example, Round Robin (RR) [3] is neither a delay-based nor a channel-based scheduling algorithm that aims to fulfill the fairness requirement while Maximum Rate (Max-Rate) [3] is a well-known channel-based scheduling algorithm developed for maximizing throughput performance. On the other hand, the Delay Prioritized Scheduling (DPS) [4] is a delay-based scheduling algorithm. The DPS does not account for the channel quality when selecting a user to receive its packets. The current trend in mobile internet usage shows an explosive request for live video streaming especially during this Covid-19 era where most daily activities have migrated to the online domain. This video streaming traffic is delay-sensitive and demands for the provision of high transmission reliability (as described in the 3GPP specifications [5]) for a huge number of live mobile video users whilst ensuring the network performance is maximized. It was shown in $[6,7]$ that channel and delay aware scheduling algorithms are the best candidates for meeting the desired QoS of this delay-sensitive live video streaming traffic and are hence considered in this paper.

An extensive number of channel and delay-based scheduling algorithms have been proposed for the legacy of wireless networks. Quite a number of these channel- and delaybased scheduling algorithms showed excellent performance in the wireless networks for which they were developed and there is a likelihood that these scheduling algorithms may perform well in the 5G LTE-A. Implementing these scheduling algorithms in the 5G LTEA may require minor amendments because the 5G LTE-A is a new wireless network and has different frameworks and features as compared to legacy wireless networks. Therefore, the contribution of this paper is the study on the adaptations of the legacy channel- and delay-based scheduling algorithms for use in the 5G LTE-A network when streaming live video.

\section{DOWNLINK 5G LTE-A NETWORK MODEL}

This paper considers the downlink 5G LTE-A given that an enormous volume of mobile internet traffic is communicated in the downlink. Orthogonal Frequency Division Multiple Access (OFDMA) is the multiple access technique employed in the downlink 5G LTE-A. This technique divides the wide bandwidth into multiple narrowband sub-carriers. The 5G LTE-A modeled in this paper modifies the legacy 4G LTE-A that performs packet scheduling at every $1 \mathrm{~ms}$ Transmission Time Interval (TTI). A total of 12 sub-carriers of $15 \mathrm{kHz}$ width each are used to carry the user packets. This group of sub-carriers (12 subcarriers) in the frequency domain and $1 \mathrm{~ms}$ TTI (that contains 14 Orthogonal Division Multiple Access (OFDM) symbols) in the time domain is referred to as Physical Resource Block (PRB). 
On the other hand, the downlink 5G LTE-A, has a variable TTI size (as illustrated in Table 1). The packet scheduler may choose to perform scheduling every $0.14 \mathrm{~ms}$ TTI for the case of delay-sensitive mobile internet traffic or every $4.0 \mathrm{~ms}$ TTI for a more delayrelaxed mobile internet traffic. This paper considers modeling the $0.14 \mathrm{~ms}$ TTI size as it aims to evaluate the scheduling algorithms for delay-sensitive live video streaming. The 0.14 ms TTI size constitutes 2 Orthogonal Division Multiple Access (OFDMA) symbols in the time domain and 12 sub-carriers in the frequency domain (see Fig. 1) for each PRB. At this TTI size also, there will be a total of 8 PRBs (as illustrated in Table 1) that map to 192 Resource Elements (REs) that will be used to carry user packets. Additionally, to further increase the 5G LTE-A performance as compared to the legacy wireless networks, the Round Trip Time (RTT) of Hybrid Automatic Repeat Request (HARQ) is shortened from $8 \mathrm{~ms}$ to $4 \mathrm{~ms}$ [8].

Table 1: TTI and Sub-band size [9].

\begin{tabular}{ccc}
\hline $\begin{array}{c}\text { TTI size } \\
(\mathbf{m s})\end{array}$ & $\begin{array}{c}\text { Frequency domain scheduling } \\
\text { block size (subband size) }\end{array}$ & $\begin{array}{c}\text { Resource Elements } \\
\text { (REs) per block size }\end{array}$ \\
\hline 0.14 & 8 PRBs $(1440 \mathrm{~Hz})$ & 192 \\
0.5 & 4 PRBs $(720 \mathrm{~Hz})$ & 336 \\
1.0 & 3 PRBs $(540 \mathrm{~Hz})$ & 432 \\
2.0 & 2 PRBs $(360 \mathrm{~Hz})$ & 576 \\
4.0 & & \\
\hline & & \\
\hline
\end{tabular}

Fig. 1: PRB time and frequency domain representation.

\section{CHANNEL AND DELAY-BASED SCHEDULING ALGORITHMS}

This paper studies eight channel- and delay-based scheduling algorithms for possible implementation in the downlink 5G LTE-A when providing the desired QoS of the delaysensitive live video streaming traffic. These algorithms are described in the following section.

\subsection{Modified-Largest Weighted Delay First (M-LWDF) Algorithm}

The M-LWDF [10] is a prominent scheduling algorithm proposed for a single-user wireless network. It should be noted that at each scheduling period, only one user is selected to receive its packets in this single-user wireless network. This is contrary to the downlink 5G LTE-A that performs packet scheduling in both time and frequency domains (i.e., more than one user can receive its packets at each scheduling period). The M-LWDF 
algorithm chooses the packets of a user that maximize Eq. (1) at each scheduling period and transmits the chosen user packets on the entire bandwidth.

$$
\begin{gathered}
\operatorname{priority}_{i}(t)=a_{i} * W_{i}(t) *\left(\frac{c q i_{i}(t)}{R_{i}(t)}\right) \\
a_{i}=-\left(\frac{\log \delta_{i}}{P D T_{i}}\right) \\
R_{i}(t)=\left(1-\frac{1}{t_{c}}\right) R_{i}(t-1)+I_{i}(t) * \frac{1}{t_{c}} * c q i_{i}(t)
\end{gathered}
$$

where $\operatorname{priority}_{i}(t)$ is the priority of the $i^{\text {th }}$ user at scheduling period $t, a_{i}$ is the desired QoS of the $i^{t h}$ user, $\delta_{i}$ is the Packet Loss Ratio (PLR) threshold of the $i^{\text {th }}$ user and $P D T_{i}$ is the packet delay threshold of the $i^{t h}$ user, $W_{i}(t)$ is the Head-of-Line (HOL) packet delay of the $i^{t h}$ user at scheduling period $t, c q i_{i}(t)$ is the channel quality of the $i^{\text {th }}$ user at scheduling period $t, R_{i}(t)$ is the average throughput of the $i^{t h}$ user at scheduling period $t, t_{c}$ is a constant and $I_{i}(t)$ is a function indicating whether the $i^{\text {th }}$ user is scheduled or not at scheduling period $t$.

\subsection{Exponential (EXP) Algorithm}

Like the M-LWDF, the EXP [11] was proposed for the single-user wireless network. The decision on which user packets to be transmitted at each scheduling period is made according to:

$$
\begin{gathered}
\operatorname{priority}_{i}(t)=a_{i} * \frac{c q i_{i}(t)}{R_{i}(t)} \exp \left(\frac{a_{i} * W_{i}(t)-a W}{1+\sqrt{a W}}\right) \\
a W=\frac{1}{N} \sum_{i=1}^{i=N} a_{i} * W_{i}(t)
\end{gathered}
$$

where $\operatorname{priority}_{i}(t)$ is the priority of the $i^{t h}$ user at scheduling period $t, a_{i}$ is the desired QoS of the $i^{\text {th }}$ user (as defined in Eq. (2)), cqi $i_{i}(t)$ is the channel quality of the $i^{\text {th }}$ user at scheduling period $t, R_{i}(t)$ is the average throughput of the $i^{t h}$ user at scheduling period $t$ (see Eq. (3)), $W_{i}(t)$ is the HOL packet delay of the $i^{t h}$ user at scheduling period $t$ and $N$ is the maximum number of available users.

\subsection{Channel-Aware Earliest Deadline (C-AED)}

The provision of the desired QoS for more users whilst maximizing network performance is the most challenging issue in the design of a packet scheduling algorithm. This is further complicated by the diverse QoS requirement of mobile internet traffic as well as the nature of the time and frequency variation of mobile wireless channels. The CAED [12] is another algorithm developed to address this complicated challenge in a single-user wireless network. Decisions on which user to receive its packets at each scheduling period are made according to:

$$
\operatorname{priority}_{i}(t)=a_{i} * \frac{c q i_{i}(t)}{R_{i}(t)}\left(\frac{W_{i}(t)}{P D T_{i}-W_{i}(t)}\right)
$$

where $\operatorname{priority}_{i}(t)$ is the priority of the $i^{\text {th }}$ user at scheduling period $t, a_{i}$ is the desired QoS of the $i^{\text {th }}$ user (as defined in Eq. (2)), cqi $i_{i}(t)$ is the channel quality of the $i^{\text {th }}$ user at scheduling period $t, R_{i}(t)$ is the average throughput of the $i^{\text {th }}$ user at scheduling period $t$ (see Eq. (3)), $W_{i}(t)$ is the HOL packet delay of the $i^{t h}$ user at scheduling period $t$ and $P D T_{i}$ is the packet delay threshold of the $i^{\text {th }}$ user. 
When compared with M-LWDF and EXP that used the desired QoS, channel quality, HOL packet delay, and average throughput criteria in their priority equations, the C-AED includes additional criterion of the packet delay threshold in its priority calculation, with the goal of improvement in performance.

\subsection{Exponential Based Packet Scheduling (EBPS) Algorithm}

The EBPS [13] algorithm was developed for use in multi-user satellite downlink Long Term Evolution (LTE) networks. The satellite LTE network aims to complement the limitations of terrestrial wireless networks by providing global coverage to users including in remote areas. This LTE network contains only one CC, and similar to the 4G LTE-A, packet scheduling in this wireless network is performed in every $1 \mathrm{~ms}$ TTI. However, contrary to single-user wireless networks, the LTE is a multi-user wireless network where more than one user can be scheduled in each TTI due to the usage of OFDMA as its multiple access technique. Packet scheduling in this LTE network is performed per PRB and time basis and the EBPS schedules packets of a user on each PRB and at each TTI according to Eq. (7).

$$
\operatorname{priority}_{i, j}(t)=\frac{\operatorname{cqi}_{i, j}(t)}{R_{i}(t)} \exp \left(\left(\frac{e}{0.99 * P D T_{i}}\right) *\left(\frac{P D T_{i}-W_{i}(t)}{W_{i}(t)}\right)\right)
$$

where $\operatorname{priority}_{i, j}(t)$ is the priority of the $i^{t h}$ user on $j^{\text {th }} \mathrm{RB}$ at TTI $t, c q i_{i, j}(t)$ is the channel quality of the $i^{\text {th }}$ user on $j^{\text {th }}$ RB at TTI $t, R_{i}(t)$ is the average throughput of the $i^{\text {th }}$ user at TTI $t$ (see Eq. (3)), $W_{i}(t)$ is the HOL packet delay of the $i^{t h}$ user at TTI $t$ and $P D T_{i}$ is the packet delay threshold of the $i^{\text {th }}$ user. It can be observed that when compared with M-LWDF, EXP and C-AED, the algorithms developed for LTE networks makes scheduling decision on each PRB and at each TTI.

\subsection{Joint User Scheduling (JUS) Algorithm}

The JUS [14] is another variation of EBPS in which the algorithm was developed by the same authors for supporting the desired QoS of delay-sensitive mobile internet traffic in the satellite LTE network. At each TTI and on each PRB the scheduling decisions are carried out based on:

$$
\operatorname{priority}_{i, j}(t)=\frac{c q i_{i, j}(t)}{R_{i}(t)} \exp \left(\frac{W_{i}(t) *\left(c q i_{i, j}(t) * P D T_{i}-1\right)+P D T_{i}}{2 W_{i}(t) *\left(1+c q i_{i, j}(t) * P D T_{i}\right)}\right)
$$

where $\operatorname{priority}_{i, j}(t)$ is the priority of the $i^{t h}$ user on $j^{\text {th }} \mathrm{RB}$ at TTI $t, c q i_{i, j}(t)$ is the channel quality of the $i^{t h}$ user on $j^{t h}$ RB at TTI $t, R_{i}(t)$ is the average throughput of the $i^{t h}$ user at TTI $t$ (see Eq. (3)), $W_{i}(t)$ is the HOL packet delay of the $i^{\text {th }}$ user at TTI $t$ and $P D T_{i}$ is the packet delay threshold of the $i^{\text {th }}$ user.

\subsection{Exponential Maximum-Largest Weighted Delay First (EXP-MLWDF)}

The EXP-MLWDF [15] was developed for use in the LTE for high mobility and dense area scenarios. The aim was to reduce congestion in LTE wireless networks due to the high use of delay-sensitive mobile internet traffic such as video streaming and voice. It was shown via a series of computer simulations that the EXP-MLWDF outperformed the M-LWDF algorithm in meeting the desired QoS for more mobile users. This algorithm decides priority of each user according to:

$$
\operatorname{priority}_{i, j}(t)=a_{i} * \frac{\operatorname{cqi}_{i, j}(t)}{R_{i}(t)} \exp \left(\frac{P D T_{i}}{P D T_{i}-W_{i}(t)}\right)
$$


where $\operatorname{priority}_{i, j}(t)$ is the priority of the $i^{\text {th }}$ user on $j^{\text {th }} \mathrm{RB}$ at TTI $t, a_{i}$ is the desired QoS of the $i^{\text {th }}$ user (as defined in Eq. (2)), $c q i_{i, j}(t)$ is the channel quality of the $i^{\text {th }}$ user on $j^{\text {th }} \mathrm{RB}$ at TTI $t, R_{i}(t)$ is the average throughput of the $i^{t h}$ user at TTI $t$ (see Eq. (3)), $P D T_{i}$ is the packet delay threshold of the $i^{\text {th }}$ user and $W_{i}(t)$ is the HOL packet delay of the $i^{\text {th }}$ user at TTI $t$.

\subsection{Downlink Scheduler Based on Deadlines (DSBD)}

Similar to the previously discussed algorithms, the DSBD [16] was developed to efficiently utilize the limited LTE radio resources and meeting the desired QoS of delaysensitive mobile internet traffic for more users. This algorithm has the following equation:

$$
\operatorname{priority}_{i, j}(t)=\frac{c q i_{i, j}(t)}{R_{i}(t) *\left(P D T_{i}-W_{i}(t)\right)}
$$

where $\operatorname{priority}_{i, j}(t)$ is the priority of the $i^{t h}$ user on $j^{t h} \mathrm{RB}$ at TTI $t, c q i_{i, j}(t)$ is the channel quality of the $i^{\text {th }}$ user on $j^{\text {th }}$ RB at TTI $t, R_{i}(t)$ is the average throughput of the $i^{t h}$ user at TTI $t$ (see Eq. (3)), $P D T_{i}$ is the packet delay threshold of the $i^{t h}$ user and $W_{i}(t)$ is the HOL packet delay of the $i^{\text {th }}$ user at TTI $t$.

\subsection{Efficient Downlink Packet Scheduling (EDPS)}

The last algorithm considered in this paper is EDPS [17] where this algorithm combines the well-known Earliest Deadline First (EDF) and Proportional Fair (PF) algorithms so as to support the transmission of delay-sensitive mobile internet packets via the downlink LTE wireless network. It should be noted that the EDF does not take channel quality into account whereas the PF does not consider packet delay in its algorithm. On each PRB and at each scheduling period, the user with the highest priority of Equation (11) will be selected to receive its packets.

$$
\operatorname{priority}_{i, j}(t)=\frac{d_{i} * W_{i}(t)}{\log \left(1+\frac{b_{i}}{W_{i}(t)}\right)+c_{i}} *\left(\frac{1}{P D T_{i}-W_{i}(t)}\right) * \frac{c q i_{i, j}(t)}{R_{i}(t)}
$$

where $\operatorname{priority}_{i, j}(t)$ is the priority of the $i^{t h}$ user on $j^{t h} \mathrm{RB}$ at TTI $t, c q i_{i, j}(t)$ is the channel quality of the $i^{\text {th }}$ user on $j^{t h} \mathrm{RB}$ at TTI $t, R_{i}(t)$ is the average throughput of the $i^{\text {th }}$ user at TTI $t$ (see Eq. (3)), $W_{i}(t)$ is the HOL packet delay of the $i^{t h}$ user at TTI $t$ and $P D T_{i}$ is the packet delay threshold of the $i^{\text {th }}$ user. It was shown in [17] that when $b_{i}, c_{i}$ and $d_{i}$ are set to 1 , the EDPS achieved good scheduling performance.

It can be observed in sub-section 3.3 through sub-section 3.8 that the conventional scheduling algorithms manipulated similar scheduling criteria but devised different priority metrics calculations in an attempt to maximize the number of users that received the desired QoS of delay-sensitive mobile internet traffic. These algorithms showed good performance in the mobile network environments they were evaluated in. However, their performance in the downlink 5G LTE-A may vary because the downlink 5G LTE-A supports slightly distinguished frameworks and features as compared to the legacy wireless networks.

As such, the contribution of this paper is to study the performance of these channel and delay-based scheduling algorithms in the downlink 5G LTE-A where minor revisions were made to these algorithms to enable them to carry out packet scheduling in this wireless network. This includes the usage of variable TTI size in which $0.14 \mathrm{~ms}$ TTI size is assumed in this paper. This, therefore, requires packet scheduling to be performed in each 8 PRBs. Moreover, the average channel quality computed from all PRBs for each CC will be considered for these algorithms instead of computing the channel quality across the 
whole bandwidth for the M-LWDF, EXP and C-AED and the channel quality on each PRB for the rest. The example of average channel quality computation is represented in Equation (12).

$$
c q i_{-} a v g_{i}(t)=\frac{\sum_{j=1}^{j=m a x \_R B} c q i_{i, j}(t)}{\max \_R B}
$$

where $c q i{ }_{-} a v g_{i}(t)$ is the average channel quality of the $i t h$ user at TTI $t, c q i_{i, j}(t)$ is the channel quality of the ith user on $j t h \mathrm{RB}$ at TTI $t$ and $\max R B$ is the total number of available RBs.

\section{SIMULATION ENVIRONMENTS}

This paper adopted a simulation method [18-20] to evaluate the performance of the studied channel and delay-based scheduling algorithms as discussed in Section 3. The downlink 5G LTE-A network was modeled to comprise of only one base station. This base station used $43.01 \mathrm{~dB}$ transmit power and operated at $2 \mathrm{GHz}$ and $2.6 \mathrm{GHz}$ CCs. Each $\mathrm{CC}$ had $5 \mathrm{MHz}$ bandwidth that mapped to a total of $50 \mathrm{PRBs}$ available to be used by the downlink users. CQI was reported by the downlink users in every $5 \mathrm{~ms}$ interval. These CQI reports reached the base station after $2 \mathrm{~ms}$ duration. Erroneously received packets at the user end could be retransmitted 4 times and the RTT of HARQ process was constrained to $4 \mathrm{~ms}$. This simulation software prioritized pending HARQ retransmission over new packets and new packets of users would only be transmitted if remaining PRBs were available after retransmission of pending HARQ packets was completed. The simulation assumed live video streaming of $512 \mathrm{kbps}$ average data rate as the delaysensitive mobile internet traffic. The delay threshold for the video users was capped at 80 $\mathrm{ms}$ and the QoS provision of the video users was met when the transmission reliability was maintained above $99.99 \%$. Table 2 summarizes the assumptions used for simulation.

Table 2: A summary of simulation assumptions

\begin{tabular}{cc}
\hline Description & Assumption \\
\hline Frequency spectrum & $2 \mathrm{GHz}$ and $2.6 \mathrm{GHz}$ \\
Bandwidth & $5 \mathrm{MHz}$ \\
Number of available RBs & $50 \mathrm{RBs}(25 \mathrm{RBs}$ each from each CC) \\
Base station transmit power & $43.01 \mathrm{~dB}$ \\
CQI & Periodic CQI every $5 \mathrm{~ms}$ with 2 ms delay \\
HARQ RTT & $4 \mathrm{~ms}$ \\
Maximum number of HARQ & 4 times \\
retransmissions & $80 \mathrm{~ms}$ and $99.99 \%$ \\
Video delay packet threshold and the \\
desired transmission reliability
\end{tabular}

Transmission reliability, average network delay, and network throughput metrics, which are considered as common metrics for the video streaming QoS provision, were used to evaluate the performance of each channel and delay-based scheduling algorithm. For example, the transmission reliability must be maintained above the $99.99 \%$ threshold to ensure that received video packets were not distorted during live streaming and hence guaranteed the desired QoS received by the live video users. The transmission reliability, as well as other metrics, are defined next: 


$$
\begin{gathered}
\text { Transmission reliability }=100-\frac{\sum_{i=1}^{i=N} \sum_{t=1}^{t=T} p_{-} \operatorname{discard}_{i}(t)}{\sum_{i=1}^{i=N} \sum_{t=1}^{t=T} p_{-} \text {total }_{i}(t)} \\
\text { Average network delay }=\frac{1}{T} \sum_{t=1}^{t=T} \frac{1}{N=N} \sum_{i=1}^{i=N} W_{i}(t) \\
\text { Network throughput }=\frac{1}{T} \sum_{i=1}^{i=N} \sum_{t=1}^{t=T} p_{-} \text {received }_{i}(t)
\end{gathered}
$$

where $p \_\operatorname{discard}_{i}(t)$ is the size of discarded packets of the $i t h$ user at time $t, p \_\operatorname{total}_{i}(t)$ is the total size of packets of the ith user that arrive at the base station at time $t, W i(t)$ is the HOL packet delay of the ith user at time $t$, $p$ _received $(t)$ is the size of correctly received packets at the ith user at time $t, T$ is the maximum simulation time and $N$ is the maximum number of users.

\section{RESULTS AND DISCUSSION}

The transmission reliability, average network delay, and network throughput performances of the channel- and delay-based scheduling algorithms in the downlink $5 \mathrm{G}$ LTE-A when streaming video are shown in Fig. 2, Fig. 3, and Fig. 4, respectively. Though all these scheduling algorithms consider the same scheduling criteria (i.e., channel quality, packet delay, etc.), the manipulation of these criteria into their respective mathematical equations map to a slight variation in performance. For example, if the QoS provision of the live video users is to be satisfied, then the transmission reliability should be kept above 99.99\%. It can be observed in Fig. 2 and Table 3 that the EXP is superior to other channel and delay-based scheduling algorithms where it supports 16\% more users compared to CAED, DSBD and EDPS (i.e., EXP supports 29 video users whereas the C-AED, DSBD, and EDPS support up to 25 users). Furthermore, it can be observed in Fig. 3 and Fig. 4 that both EXP and M-LWDF are capable of minimizing the average network delay as well as maximizing the network throughput. Both EXP and the M-LWDF prioritize the most urgent packets to avoid these packets from being discarded for delay violations and hence minimize the average network delay. The network throughput on the other hand is the most important metric for the network operator for profit maximization. Therefore, the EXP and M-LWDF are preferred as these algorithms provide higher network throughput as compared to the other evaluated scheduling algorithms.

The achievement accomplished by EXP and M-LWDF, as illustrated in Table 3, is significant given that mobile users are streaming live video at an average rate of $512 \mathrm{kbps}$. The EXP outperforms other scheduling algorithms because EXP computes the average of the desired QoS and the HOL packet delay. This, however, incurs additional computational complexity because the extra step is needed in determining the priority of each user at each TTI (the downlink 5G LTE-A network is already complex and additional complexity in a scheduling algorithm is not preferred). The M-LWDF algorithm, on the other hand, has a simple mathematical equation and achieves slightly lower performance compared to the EXP. It supports $12 \%$ more video users as compared to C-AED, DSBD and EDPS and is capable of minimizing average network delay whilst maximizing the network throughput (as demonstrated in Fig. 3 and Fig. 4). It also does not come with additional computational complexity as does EXP. Other variations of mathematical equations lead to worse performance as in C-AED, DSBD, and EDPS whereas more complex mathematical equations do not necessarily map to good video performance (see the EBPS, JUS, EXP-MLWDF algorithms). 


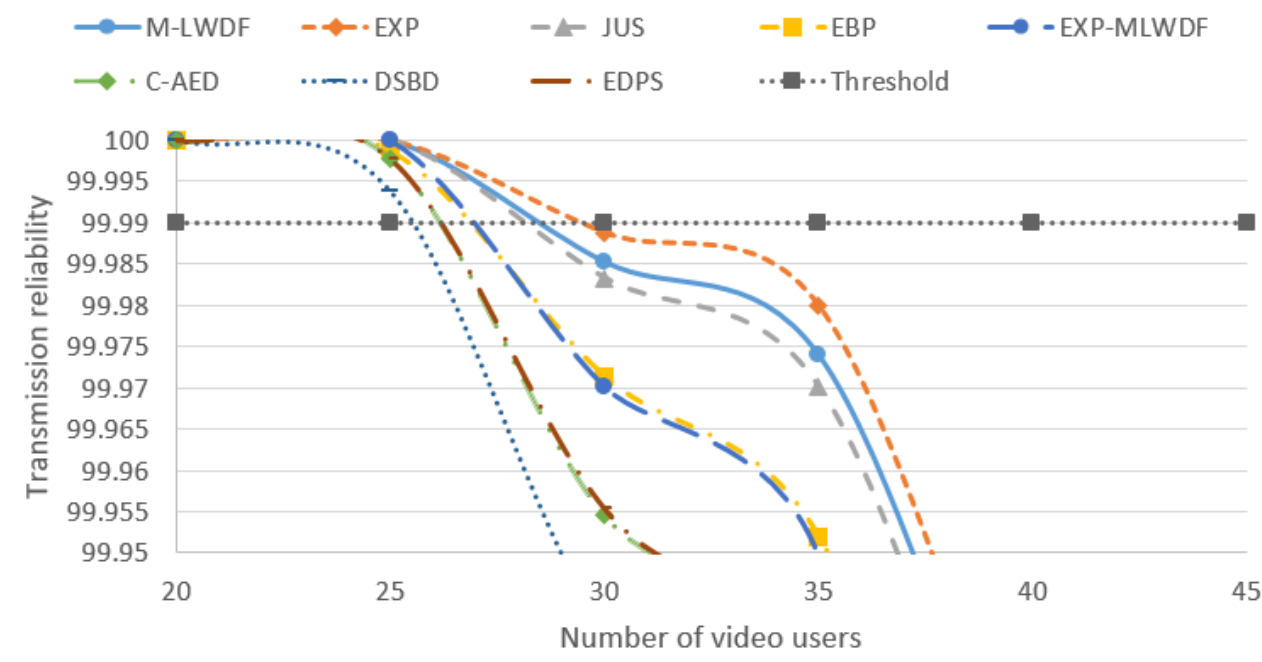

Fig. 2: Transmission reliability vs number of video users.

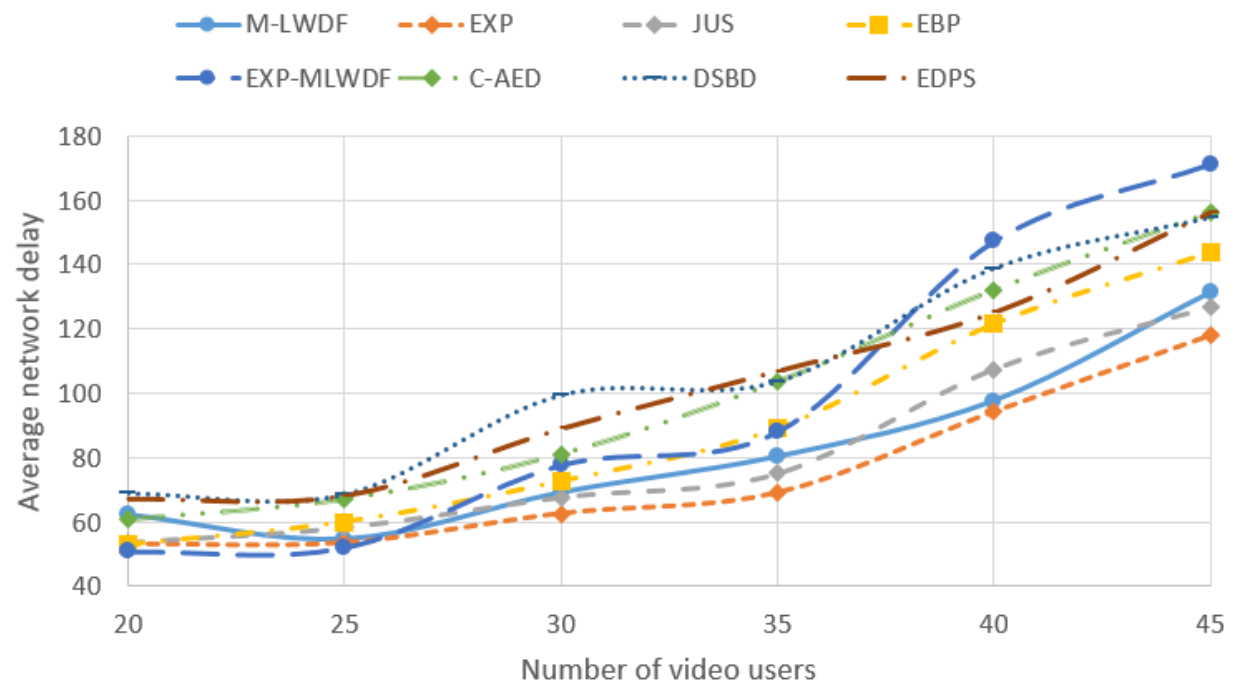

Fig. 3: Average network delay vs number of video users.

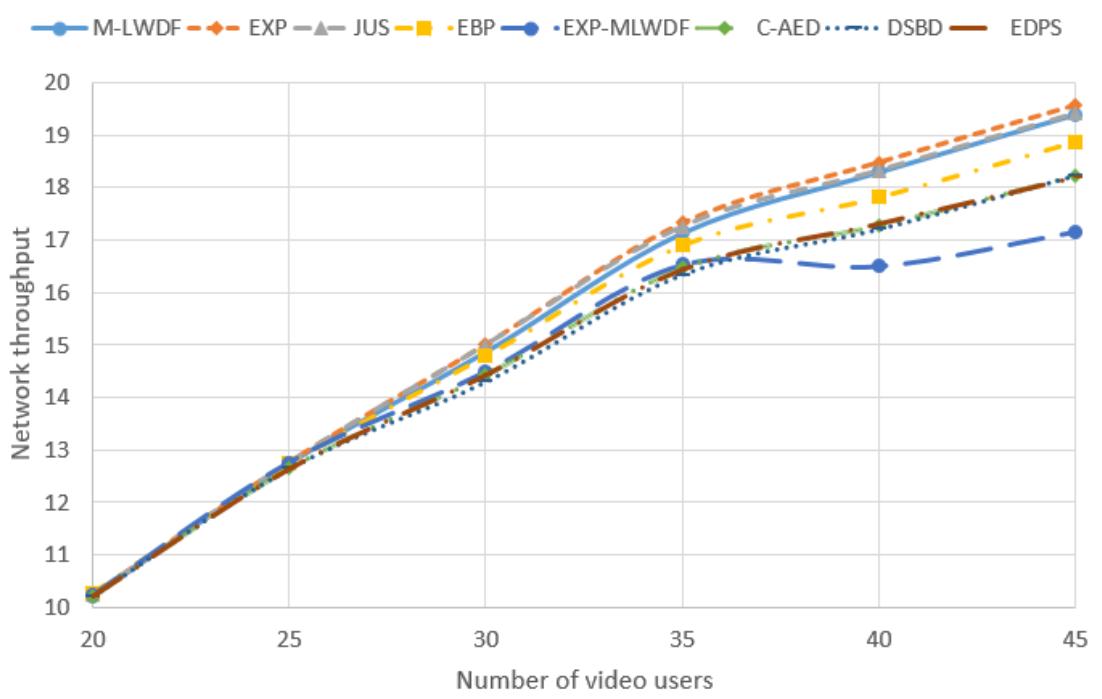

Fig. 4: Network throughput vs number of video users. 
Table 3: Maximum number of users at desired video QoS provision

\begin{tabular}{cc}
\hline Scheduling algorithms & $\begin{array}{c}\text { Maximum number of users at } \\
\text { desired live video QoS provision }\end{array}$ \\
\hline M-LWDF & 28 \\
EXP & 29 \\
C-AED & 25 \\
EBPS & 26 \\
JUS & 27 \\
EXP-MLWDF & 26 \\
DSBD & 25 \\
EDPS & 25 \\
\hline
\end{tabular}

\section{CONCLUSION}

The enormous demand for video streaming traffic has accelerated the standardization of $5 \mathrm{G}$ wireless networks. Packet scheduling is of paramount importance in the $5 \mathrm{G}$ wireless to efficiently utilize the scarce radio resources and provide satisfactory QoS provisions of the diverse mobile internet traffic. This paper studies the performance of channel- and delay-based scheduling algorithms in the downlink 5G LTE-A wireless network when streaming live video. Minor amendments were made to these algorithms because the frameworks and features of the downlink 5G LTE-A are slightly different from legacy wireless networks. A series of computer simulations demonstrated that the EXP outperforms other scheduling algorithms however, this algorithm incurs additional complexity for calculating the average of the desired QoS and the HOL packet delay at every TTI. The M-LWDF seems the most eligible candidate because its performance is comparable to EXP, and it does not come with an additional complexity cost. It supports $12 \%$ more users streaming video at $512 \mathrm{kbps}$ average data rate, minimizing the average network delay and maximizing the network throughput. It can also be concluded, based on this study, that complex mathematical equations sometimes do not necessarily map to a good scheduling performance. What is most important is the exploitation of these scheduling criteria to effectively meet the desired QoS for a huge number of users and maximizing the network performance. Future works will investigate the performance of these algorithms in a multiple cell scenario, considering diverse mobile internet traffic.

\section{ACKNOWLEDGEMENT}

This work was fully funded by UTM CRG no. 08G12.

\section{REFERENCES}

[1] Nordin MAM, Ramli HAM. (2020) Performance analysis of 5G path loss models for rural macrocell environment. IIUM Eng. J., 21(1): 85-99.

[2] Antonioli RP, Fodor G, Soldati P, Maciel TF. (2021) Decentralized Joint Beamforming, User Scheduling, and QoS Management in 5G and Beyond Systems. IEEE Commun. Stand. Mag., 5(1):62-69.

[3] Dahlman E, Parkvall S, Skold J, Beming P. (2007) 3G Evolution: HSPA and LTE for Mobile Broadband. Elsevier Ltd.

[4] Sandrasegaran K, Ramli HAM, Basukala R. (2010) Delay-Prioritized Scheduling (DPS) for Real Time Traffic in 3GPP LTE System, in IEEE Wireless Communication and Networking Conference, pp. 1-5.

[5] 3GPP (2019) Technical Specification Group Services and System Aspects; System 
architecture for the 5G System (5GS); Stage 2 (Release 16).

[6] Ramli HAM, Basukala R, Sandrasegaran K, Patachaianand R. (2009) Performance of well known packet scheduling algorithms in the downlink 3GPP LTE system, in 2009 IEEE 9th Malaysia international conference on communications (MICC), pp. 815-820.

[7] Ramli HAM, Isa FNM. (2016) Improving real-time multimedia scheduling in practical mobile cellular channels, in IEEE 6th International Conference on Intelligent and Advanced Systems (ICIAS), pp. 1-6.

[8] Pocovi G, Soret B, Pedersen KI, aMogensen P. (2017) MAC layer enhancements for ultrareliable low-latency communications in cellular networks, in IEEE International Conference on Communications Workshops, pp. 1005-1010.

[9] Pedersen KI, Niparko M, Steiner J, Oszmianski J, Mudolo L, Khosravirad SR. (2016) System level analysis of dynamic user-centric scheduling for a flexible 5G design, in IEEE Global Communications Conference, pp. 1-6.

[10] MathewA, Kumaran K, Ramanan K, Stolyar A, Whiting P. (2001) Providing Quality of Service over a Shared Wireless Link. IEEE Commun., 39(2):150-154.

[11] Shakkotai S, Stolyar A. (2000) A Study of Scheduling Algorithms for a Mixture of Real- and Non-Real-Time Data in HDR, Bell Labs Tech Memo.

[12] Elsayed KMF, Khattab AKF. (2006) Channel-Aware Earliest Deadline Due Fair Scheduling for Wireless Multimedia Networks. Wirel. Pers. Commun., 38:233-252.

[13] Aiyetoro G, Takawira F. (2017) An exponential based packet scheduling scheme for real time traffic in satellite LTE networks, in IEEE AFRICON, pp. 215-220.

[14] Aiyetoro G, Takawira F. (2018) Joint User Scheduling and PRB Mapping Scheme in Satellite LTE Networks, in 4th International Wireless Communications \& Mobile Computing Conference (IWCMC), pp. 24-29.

[15] Angri I, Mahfoudi M, Najid A, El Bekkali M. (2018) Exponential M-LWDF (EXP-MLWDF) Downlink Scheduling Algorithm Evaluated in LTE for High Mobility and Dense Area Scenario. Int. J. Electr. Comput. Eng., 8(3):1618-1627.

[16] Ashidani PJ, Guardieiro PR. (2013) Downlink Scheduler Based on Deadlines for LTE Networks, in International workshop on telecommunications (IWT), pp. 1-5.

[17] Liu B, Tian H, Xu L. (2013) An Efficient Downlink Packet Scheduling Algorithm for Real Time Traffics in LTE Systems, in IEEE 10th Consumer Communications and Networking Conference (CCNC), pp. 364-369.

[18] Ramli HAM, Isa FNM, Asnawi AL, Jusoh AZ, Azman AW. (2019) Urgency-Aware Scheduling Algorithm for Downlink Cognitive Long Term Evolution-Advanced, in IEEE 89th Vehicular Technology Conference (VTC Spring), pp. 1-5.

[19] Ramli HAM, Mansor MIH. (2020) An enhanced packet scheduling algorithm for the downlink cognitive long term evolution-advanced. IIUM Eng. J., 21(1):51-60.

[20] Ramli HAM. (2020) A study on packet scheduling algorithms for healthcare contents over fifth generation (5G) mobile cellular network. Int. J. Electron. Telecommun., 66(4):1-7. 